\title{
ANALYSIS OF INDIVIDUAL, PHYSICAL, AND PSYCHOSOCIAL RISK FACTORS ON WORK-RELATED SKELETAL MUSCLE DISORDERS IN WORKERS IN TOURISM SECTOR: A SYSTEMATIC REVIEW
}

\author{
Muhammad Luthfi, Baiduri Widanarko
}

Occupational Safety and Health Program, Faculty of Public Health, Universitas Indonesia

\begin{abstract}
Background: Based on observations and interviews conducted with workers in the tourism sector, there were subjective complaints of work-related skeletal muscle disorders experienced by workers. But it was still an inadequate explanation of the cause of workrelated skeletal muscle disorders in workers. This study aimed to investigate the analysis of individual, physical, and psychosocial risk factors on work-related skeletal muscle disorders in workers at the tourism sector.

Subjects and Method: A systematic review was conducted by searching from PubMed, Science Direct, and Scopus databases. The inclusion criteria were the studies identifying the association of individual, physical, and psychosocial risk factors with work-related skeletal muscle disorders in workers of the tourism sector. The articles must be published full texts in English-language between 2005 and 2020. The quality, measure of association, and level of evidence of the selected studies were critically appraised. The data were reported according to PRISMA flow chart.

Results: Twelve articles, consisting of ten cross-sectional, one exploratory, and one cohort study designs, were obtained. The study subjects worked at hotels and restaurants. Nine articles showed high quality, and the other three articles showed low-quality. These articles reported an association between risk factors and work-related skeletal muscle disorders. The individual, physical, and psychosocial risk factors included gender, BMI, repetitive motion, excessive reaching, and the number of room cleaning per day.

Conclusion: Twelve articles with different quality show the association between risk factors and work-related skeletal muscle disorders. The risk factors include gender, BMI, repetitive motion, excessive reaching, and the number of room cleaning per day in workers of the tourism sector.
\end{abstract}

Keywords: work-related skeletal muscle disorders, risk factors, ergonomy, tourism

\section{Correspondence:}

Muhammad Luthfi. Occupational Safety and Health Program, Faculty of Public Health, Universitas Indonesia. Email: Muhluthfi93@gmail.com. Mobile: 082220279794.

The $7^{\text {th }}$ International Conference on Public Health Solo, Indonesia, November 18-19, $2020 \mid 73$ https://doi.org/10.26911/the7thicph.01.28 